Fetal Diagnosis and Therapy
Fetal Diagn Ther 2018;43:12-18

DOI: $10.1159 / 000464246$
Received: October 24, 2016

Accepted after revision: February 16, 2017

Published online: March 21, 2017

\title{
Right Congenital Diaphragmatic Hernias: \\ Is There a Correlation between Prenatal Lung Volume and Postnatal Survival, as in Isolated Left Diaphragmatic Hernias?
}

\author{
Teresa Victoria $^{a, b}$ Enrico Danzer ${ }^{a} \quad$ Edward R. Oliver ${ }^{a, b} \quad J$. Christopher Edgar ${ }^{b}$ \\ Suzanne lyoob ${ }^{a}$ Emily A. Partridge ${ }^{a}$ Ann M. Johnson ${ }^{a, b}$ William H. Peranteau ${ }^{a}$ \\ Beverly G. Coleman ${ }^{a, b}$ Alan W. Flake ${ }^{a}$ Mark P. Johnson ${ }^{a}$ Holly H. Hedrick ${ }^{a}$ \\ N. Scott Adzick ${ }^{a}$ \\ ${ }^{a}$ Center for Fetal Diagnosis and Treatment, and ${ }^{b}$ Radiology Department, Children's Hospital of Philadelphia, \\ Philadelphia, PA, USA
}

\section{Keywords}

Congenital diaphragmatic hernia · Fetal surgery · Prenatal imaging $\cdot$ Fetal magnetic resonance imaging $\cdot$ Fetal lung volume measurement $\cdot$ Fetal endoscopic tracheal occlusion

\begin{abstract}
Objectives: Whereas left-sided congenital diaphragmatic hernias $(\mathrm{L}-\mathrm{CDH})$ have been extensively studied and their prognostic parameters delineated, right-sided hernias ( $\mathrm{R}$ $\mathrm{CDH}$ ) have not. Published results remain inconclusive. The aim of this study is to evaluate if proven prognostic indicators of postnatal survival in the fetus with L-CDH apply to the fetus with R-CDH. Methods: Retrospective single-center study of R-CDH fetuses with available prenatal studies assessed for fetal lung volume by means of ultrasound-measured observed versus expected (O/E) lung area to head circumference (LHR) and magnetic resonance-calculated O/E total lung volume (TLV) in a 12-year time period. Percentage of herniated liver volume and postnatal use of extracorpo-
\end{abstract}

(C) 2017 S. Karger AG, Basel
E-Mail karger@karger.com

www.karger.com/fdt real membrane oxygenation (ECMO) were also evaluated. Results: In a cohort of 24 patients, O/E LHR, O/E TLV, percentage of herniated liver, and postnatal use of ECMO are not prognostic indicators of survival in the fetus with $\mathrm{R}-\mathrm{CDH}$. Cut-off values of O/E LHR of $\leq 45$ or O/E TLV $\leq 25$, known to select a population of severe cases for the L-CDH fetus, do not appear to extrapolate to the R-CDH fetus, as survival in both $\mathrm{R}-\mathrm{CDH}$ groups is $60 \%$. Conclusion: The findings in this study suggest that L- and R-CDH appear to behave differently, and that factors that make L-CDH fatal (low O/E TLV and O/E LHR, high-volume herniated liver) may not apply to the fetus with $\mathrm{R}-\mathrm{CDH}$.

(c) 2017 S. Karger AG, Basel

\section{Introduction}

Congenital diaphragmatic hernia $(\mathrm{CDH})$ results from a developmental defect in the diaphragm that allows the abdominal viscera to herniate into the chest, leading to

Teresa Victoria, MD, $\mathrm{PhD}$

Center for Fetal Diagnosis and Treatment, Radiology Department The Children's Hospital of Philadelphia

34th Street and Civic Center Boulevard, Philadelphia, PA 10104 (USA)

E-Mail victoria@email.chop.edu 
varying degrees of lung compression, pulmonary hypoplasia, and pulmonary hypertension. $\mathrm{CDH}$ has a prevalence of about 1-4 per 10,000 births, of which approximately $85 \%$ are left-sided (L-CDH), $13 \%$ are right-sided (R-CDH), and $2 \%$ are bilateral. Prognostic indicators of postnatal survival in the fetus with $\mathrm{L}-\mathrm{CDH}$ have been extensively evaluated in the past, including the presence of herniated intrathoracic liver and the degree of lung hypoplasia as reflected by the measured fetal lung volumes [15]. Because of its relative infrequency, R-CDH has rarely been studied. When examined, results have been inconclusive and contradictory. In this paper, we evaluate if previously proven prognostic indicators of postnatal outcome in the fetus with L-CDH apply to the fetus with R$\mathrm{CDH}$. Since virtually all R-CDH cases have herniated intrathoracic liver, the study focuses on the evaluation of fetal lung volumes as measured by both magnetic resonance (MR) imaging and ultrasound (US).

\section{Materials and Methods}

\section{Patient Selection}

The study was done after obtaining approval from the Institutional Review Board. A retrospective search of the radiology database at the Center for Fetal Diagnosis and Treatment at the Children's Hospital of Philadelphia extending from July 2002 until June 2014 was undertaken searching for the terms "right CDH" and "right congenital diaphragmatic hernia." Inclusion criteria were: (1) patients with available prenatal US and/or MR, (2) patients managed expectantly prenatally. Exclusion criteria: (1) technically limited US or MR, (2) no prenatal workup at our hospital, (3) no postnatal follow-up, (4) additional lung lesions, (5) additional lesions/findings that affect normal pulmonary development, (6) incorrect diagnosis.

\section{Imaging Evaluation}

The standard imaging evaluation of the fetus with suspected $\mathrm{CDH}$ at our center includes US, MR, and echocardiography, all obtained in a single day. Additional genetic workup is done if deemed necessary.

The US examination included a detailed evaluation to confirm the diagnosis and to exclude additional structural anomalies. Hydrops was defined as the accumulation of fluid in at least two fetal compartments. Liver position and measurement of the contralateral lung area to head circumference (LHR) were determined following published techniques [6] and obtained by a pediatric radiologist with 7 years of fetal experience. Briefly, the left lung area was calculated as the product of two orthogonal linear measurements (in millimeters) of the left lung obtained at the level of the four-chamber heart view, with an anterior-posterior measurement obtained parallel to the sternovertebral body axis and a transverse measurement obtained perpendicular to the sternovertebral body axis. The LHR was calculated as the ratio of left lung area (in square millimeters) to head circumference (in millimeters). The observed versus expected $(\mathrm{O} / \mathrm{E}) \mathrm{LHR}$ was calculated for $\mathrm{R}-\mathrm{CDH}$ using the online TOTAL trial LHR calculator (www.totaltrial.eu) and the lung measurements, head circumference, and expected gestational age (in weeks and days) of the fetus at the time of evaluation $[7,8]$.

$\mathrm{MR}$ imaging was done at $1.5 \mathrm{~T}$ or $3 \mathrm{~T}$ using established protocols $[1,9]$. No maternal sedation was administered during the study. Sequences obtained for lung measurement were obtained in the axial plane to the fetal lung with a $3-\mathrm{mm}$ slice thickness and no gap. Sequences covered the fetal lung in a single acquisition and had no fetal motion. Calculations of fetal lung volumes were as previously reported [1] and done by a pediatric radiologist with over 10 years of fetal experience. Briefly, the lung tissue visible on each section through the chest was manually outlined in each slice of a single sequence. The areas obtained from each slice were summed separately for each lung field and converted to a volume by multiplying times the slice thickness. The ratio of $\mathrm{O} / \mathrm{E}$ total lung volume (TLV) was calculated by dividing the number obtained for the TLV (both right and left lungs) by that expected for gestational age from the reference tables. The references used for expected volumes were as published by Rypens et al. [10] for $\geq 21$ weeks of gestation or Ward et al. [11] for $<21$ weeks.

For the calculation of liver volume, a sagittal or coronal sequence of the fetus was selected that included the entire liver without significant fetal motion. A portion of the visualized diaphragm provided a boundary for determining whether the liver was intrathoracic or intra-abdominal. The volume of herniated liver was calculated following the same tracing technique described above for the lung, including manual outlining of the hepatic surface above and below the diaphragmatic boundary. The areas were then summed separately and multiplied by slice thickness to yield a final volume of supradiaphragmatic and infradiaphragmatic liver. A simple percentage ratio ([volume liver up/total liver volume] $\times 100)$ was calculated to obtain a final estimation of herniated intrathoracic liver.

\section{Medical Data Collection and Perinatal Care}

All prenatal and postnatal charts of the cases included were reviewed. Institutional prenatal and postnatal care was standardized as previously published $[12,13]$. Briefly, for birth planning, vaginal deliveries were favored, unless there were standard obstetric indications for cesarean section, including failure to progress or evidence of fetal compromise. Induction of labor was planned around 38-39 weeks of gestation, which allowed for a controlled birth where the care team was appropriately assembled $[12,13]$.

The extracorporeal membrane oxygenation (ECMO) data were collected from chart review. The criteria for ECMO use at our institution include the inability to maintain preductal oxygen saturation $>85 \%$; peak inspiratory pressure $>28 \mathrm{~cm} \mathrm{H}_{2} \mathrm{O}$, mean airway pressure $>15$; pressor-resistant hypotension; inadequate oxygen delivery based on persistent metabolic acidosis or rising serum lactate level; and inability to wean from $\mathrm{FiO}_{2} 100 \%$ in the first $48 \mathrm{~h}$ of life. Inclusion criteria also include birth weight $>2 \mathrm{~kg}$, gestational age $>34$ weeks, absence of intracranial hemorrhage $>$ grade I, and absence of other significant congenital or chromosomal anomalies [13]. Postnatal survival was defined as discharge from the hospital.

\section{Statistical Analysis}

Summary statistics are presented as means \pm standard deviation for continuous variables and frequency distributions for categorical variables. Associations between outcomes were evaluated using $\chi^{2}$ tests for categorical values and $t$ tests to compare mean values for continuous variables. The significance level was defined as $p<0.05$.

Right Congenital Diaphragmatic Hernias

Fetal Diagn Ther 2018;43:12-18 


\section{Results}

\section{Patient Population}

Search of the radiology database yielded $30 \mathrm{R}-\mathrm{CDH}$ patients with available prenatal imaging. Six of these patients were excluded secondary to the presence of additional lung lesions $(n=3)$, wrong diagnosis $(n=2)$, and one with additional congenital abnormalities affecting lung development (suspected posterior urethral valves with significant obstructive uropathy, absence of one kidney and dysplastic contralateral kidney). Of the remaining 24, 1 was excluded from the MR arm of the study as the images were technically limited, leaving a study group of 23. In the US arm of the study, of the 24 cases initially evaluated, 2 cases had a gestational age $>32$ weeks (which precludes calculation of O/E LHR as there are no standard lung volumes for that gestational age), and 1 was excluded on basis of inadequate US to measure an LHR value at the 4 -chamber level. The final group of cases available for the US arm was thus 21 . Of the final tally of patients, 20 had both US and MR studies for evaluation, 3 only MR studies, and 1 only US. The total number of patients included for MR and/or US review was 24 (Fig. 1). Two of the included patients had congenital heart disease, one with ventricular septal defect (known not to impact pulmonary development) and a second case with hypoplastic left heart syndrome (HLHS). The HLHS case was included in the examination, as it did not demonstrate MR findings of pulmonary lymphangiectasia, a known pulmonary complication of HLHS [14].

Maternal age at initial evaluation in the 24 cases that comprised the study ranged from 19 to 48 years (mean 31 \pm 7 ), with a gestational age range at first intake of 19-34 weeks (mean $25 \pm 7$ ). At the time of delivery, gestational age ranged from 31 to 40 weeks (mean $37 \pm 2$ ) and birth weight from 1,240 to $4,000 \mathrm{~g}$ (mean 2,950 \pm 623 ). Of the 24 cases, 8 were female and 16 were male. Two of the included cases were part of separate dichorionic diamniotic pregnancies where the co-twins were unaffected.

\section{Survival}

Of the 24 cases included, 15 (63\%) survived to discharge (mortality: 37\%). All 24 cases had liver and bowel herniated in the thorax. In all but 3 cases, the gallbladder was also intrathoracic (1 was intra-abdominal, 2 could not be conclusively assessed). Only 1 case demonstrated hydrops (severe), also the only stillborn. Of the remaining 8 nonsurvivors, 5 died on the first day of life, 1 on the 17 th day of life, another on the 28th, and the last died at 1 month of life.

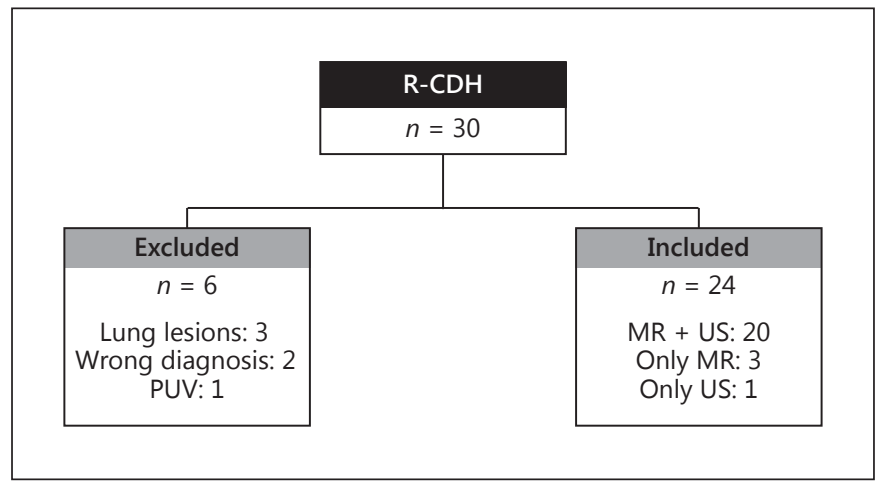

Fig. 1. Study population. Of the 30 initial cases, 6 were excluded yielding a final study population of 24 . Of these, 20 had both ultrasound (US) and magnetic resonance (MR), while 3 had only MR and 1 only US. R-CDH, right-sided congenital diaphragmatic hernia; PUV, posterior urethral valves.

Table 1. Overall lung volume measurements subdivided by survival

\begin{tabular}{llll}
\hline & MR TLV & $\begin{array}{l}\text { O/E TLV } \\
(\mathrm{MR})\end{array}$ & $\begin{array}{l}\text { O/E LHR } \\
\text { (US) }\end{array}$ \\
\hline Survivors & $7.9 \pm 3.2 \mathrm{~mL}$ & $26 \pm 12$ & $57 \pm 13$ \\
& $n=15$ & $n=15$ & $n=15$ \\
Nonsurvivors & $9.4 \pm 5 \mathrm{~mL}$ & $21 \pm 5$ & $65 \pm 27$ \\
& $n=8$ & $n=8$ & $n=6$ \\
$p$ value & 0.38 & 0.14 & 0.35 \\
\hline
\end{tabular}

No statistical difference was observed between survivors and nonsurvivors when evaluating different modalities of lung measurements. MR, magnetic resonance; US, ultrasound; O/E, observed versus expected; TLV, total lung volume; LHR, lung area to head circumference.

\section{Lung Volumes}

In two cases, the ipsilateral lung to the hernia was not visualized by MR. The mean MR right lung volume for our cohort of 23 was $1.8 \pm 1 \mathrm{~mL}$, mean left lung volume $6.7 \pm 3 \mathrm{~mL}$, and mean TLV $8.4 \pm 4 \mathrm{~mL}$. Calculated MR $\mathrm{O} / \mathrm{E}$ TLV ranged from 10 to $48 \%$, with a mean of $24 \pm 10$.

Lung volume measurements were subdivided based on survival (Table 1). Two-tailed $t$ test showed no statistical difference in MR-calculated TLVs of survivors versus nonsurvivors (7.9 vs. $9.4 \mathrm{~mL} ; t[21]=0.90 ; p=0.38$ ), nor in the O/E LHR (57 vs. $65 ; t[19]=0.96 ; p=0.35$ ) or MRcalculated O/E TLV (26 vs. $21 ; t[21]=1.56 ; p=0.14)$. Of note, the pattern of findings was the same using nonparametric Mann-Whitney U tests.

When lung volumes were stratified according to an $\mathrm{O} / \mathrm{E}$ TLV value of 25 (previously reported to predict sur-
Victoria et al. 
vival in fetuses with L-CDH [1]), Fisher exact test showed no differences in survival for R-CDH $(p=0.66)$ (Table 2). The mean MR-calculated O/E TLV value was 18 in survivors versus 19 in nonsurvivors for those with $\mathrm{O} / \mathrm{E}<25$. In those with $\mathrm{O} / \mathrm{E} \geq 25$, the value was 38 in survivors versus 27 in nonsurvivors. Of the 15 cases with $\mathrm{O} / \mathrm{E} \mathrm{TLV}<25,9$ survived ( $60 \%$ survival); in those with $\mathrm{O} / \mathrm{E}$ TLV $\geq 25$, survival was $75 \%$ or $6 / 8$ (Fig. 2 ).

Another marker of severe pulmonary hypoplasia is the US-calculated O/E LHR. An O/E LHR of $\leq 45 \%$ has been shown to indicate severe pulmonary hypoplasia [15]. In the present study, 5 patients had an O/E LHR $\leq 45$ (range $30-44$, mean 40 ), of whom 3 survived (60\% survival). In the O/E LHR $>45$ group $(n=16)$, the range was $46-96$, mean 67,4 of whom succumbed to the disease (75\% survival). $\chi^{2}$ test showed no difference in survival rates in the group with $\mathrm{O} / \mathrm{E} \mathrm{LHR} \leq 45$ versus those with $\mathrm{O} / \mathrm{E} \mathrm{LHR}>45$ $(p=0.60)$. In fact, the O/E LHR of those that died in the $>45$ group were among the highest values (90 and 96).

\section{MR Liver Volume}

All of the fetuses in our study had liver up. To evaluate if the overall volume of intrathoracic liver predicted survival, the percentage of herniated liver was calculated on MR and plotted against survival (Table 3 ). The average percentage of herniated liver was $35 \pm 13 \%$ in survivors versus $38 \pm 9 \%$ in nonsurvivors, with the results being not statistically different $(t[19]=0.53 ; p=0.60)$. Additional evaluation between percentage of herniated liver versus $\mathrm{O} / \mathrm{E}$ LHR and O/E TLV showed no statistical difference ( $p=0.1$ and 0.3 , respectively).

\section{Additional Findings}

All cases had herniated intrathoracic bowel in addition to liver (Table 4). In all but 3 cases, the gallbladder was in an intrathoracic position; in 1 case, it was intra-abdominal and in the remaining 2 cases, it could not be conclusively determined.

Pleural fluid was seen in all but 1 case, ranging from trace to a case of frank hydrops with large effusions and ascites in a stillborn.

Of the 24 cases, 15 were delivered at our institution (10 survivors) and 9 were transferred after birth from outside hospitals to be treated at our center ( 5 survivors), with no statistical difference in survival if the delivery was inhouse or referred immediately after birth $(p=0.6)$.

Of the 24 cases, 1 was a stillbirth and 2 died immediately after birth. Of the remaining 21 cases, ECMO was utilized postnatally in 12 of them, of which 8 survived. Of the 9 patients who did not receive ECMO, 7 survived (the

Right Congenital Diaphragmatic Hernias

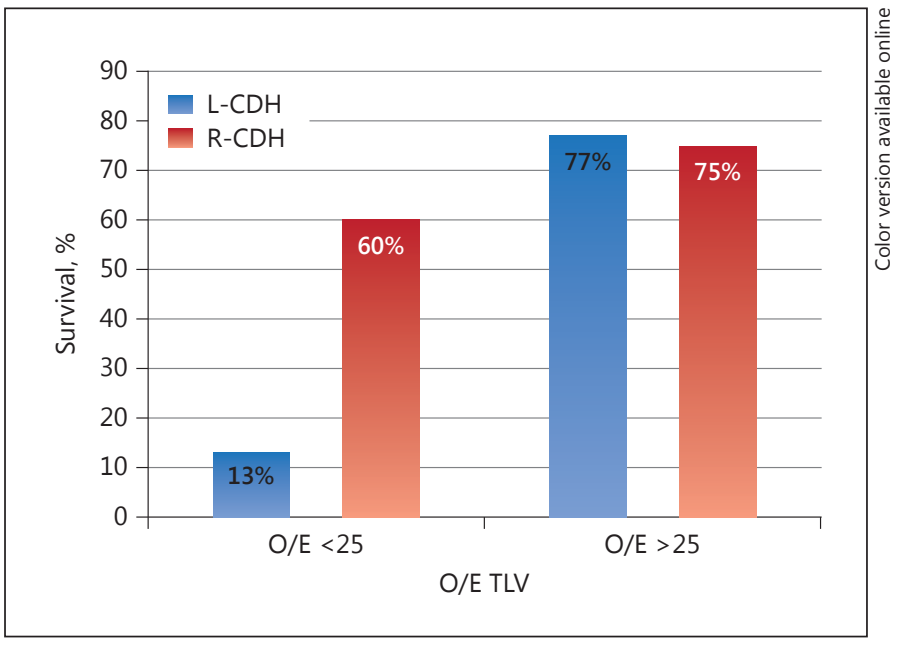

Fig. 2. Comparison of survival of left- (L-CDH) versus right-sided congenital diaphragmatic hernia (R-CDH) fetuses with respect to observed versus expected (O/E) total lung volume (TLV). Data from L-CDH survival comes from a previously published manuscript generated at our institution [1].

Table 2. Survival based on magnetic resonance (MR)-calculated observed versus expected $(\mathrm{O} / \mathrm{E})$ total lung volume

\begin{tabular}{lll}
\hline & $\begin{array}{l}\text { MR O/E <25 } \\
\text { mean (range) }\end{array}$ & $\begin{array}{l}\text { MR O/E 25 } \\
\text { mean (range) }\end{array}$ \\
\hline Survivors & $18(14-23)$ & $38(25-48)$ \\
& $n=9$ & $n=6$ \\
Nonsurvivors & $19(10-23)$ & $\begin{array}{l}27(26-27) \\
n=2\end{array}$ \\
& $n=6$ & $n=2$ \\
\hline
\end{tabular}

Fisher exact test showed no significant difference in survival $(p=0.66)$ when $\mathrm{O} / \mathrm{E}$ total lung volume was split at a value of 25 , a known predictor of mortality in fetuses with left-sided congenital diaphragmatic hernia [1].

Table 3. Evaluation of herniated intrathoracic liver volume and survival

Percentage herniated liver (range)

\begin{tabular}{ll}
\hline Survivors & $35 \%(9-59)$ \\
& $n=14^{*}$ \\
Nonsurvivors & $38 \%(25-50)$ \\
& $n=7^{*}$ \\
$p$ value & 0.60 \\
\hline
\end{tabular}

A $t$ test analysis showed no difference between volume of herniated liver and postnatal survival. * Liver volume could not be technically measured in 1 case of the survivor group and 1 case of the nonsurvivor group. 
Table 4. Additional fetal findings in the included cases

\begin{tabular}{llllllll}
\hline $\begin{array}{l}\text { Herniated } \\
\text { bowel } \\
n=24\end{array}$ & $\begin{array}{l}\text { Herniated } \\
\text { gallbladder } \\
n=22^{*}\end{array}$ & $\begin{array}{l}\text { Pleural } \\
\text { fluid } \\
n=24\end{array}$ & $\begin{array}{l}\text { ECMO } \\
n=21^{* *}\end{array}$ & $\begin{array}{l}\text { Hydrops } \\
n=24\end{array}$ & $\begin{array}{l}\text { Additional fetal } \\
\text { anomalies } \\
n=24\end{array}$ & $\begin{array}{l}\text { In-house } \\
\text { birth } \\
n=24\end{array}$ \\
\hline 24 & 21 & 23 & $\begin{array}{l}12 \\
(8\end{array}$ & $\begin{array}{l}\text { no } \\
\text { survivors })\end{array}$ & $\begin{array}{l}(7 \\
\text { survivors })\end{array}$ & & $\begin{array}{l}\text { Imperforate anus }(n=1) \\
\text { IUGR }(n=1) \\
\text { Vertebral anomalies }(n=1) \\
\text { VSD }(n=1)\end{array}$ \\
\end{tabular}

ECMO, extracorporeal membrane oxygenation; HLHS, hypoplastic left heart syndrome; IUGR, intrauterine growth restriction; VSD, ventricular septal defect.* In 2 cases, the anatomic location of the gallbladder could not be conclusively determined. ** Two patients died shortly after birth and 1 was a stillbirth.

2 remaining died before ECMO could be initiated). $\chi^{2}$ test showed no statistical difference in survival if ECMO was administered postnatally $(p=0.66)$.

\section{Discussion}

The low incidence of R-CDH has limited our understanding of the disease. Prognostic indicators for survival usually applied to L-CDH have been extrapolated and used as survival indicators for the R-CDH fetus, a practice that is not necessarily accurate. In this study examining a cohort of 24 patients with available prenatal imaging, prognostic factors associated with postnatal outcome in fetuses with L-CDH, including O/E TLV, O/E LHR, and postnatal use of ECMO, were not found to predict postnatal survival in fetuses with $\mathrm{R}-\mathrm{CDH}$.

The overall survival in our study was $63 \%$ which, coincidentally, is similar to the overall survival in an L-CDH cohort from a previously reported study at our center [1]. These R-CDH survival rates can be compared to $70 \%$ survival of R-CDH cases reported from the Texas Children's Hospital group ( $n=37)$ [16], 59\% of the University of California, San Francisco group $(n=34)$ [17], and 53\% from the European consortium $(n=19)$ [15].

A strong predictor of outcome in the fetus with $\mathrm{L}-\mathrm{CDH}$ is the intrathoracic position of the liver, or "liver up." In the case of the R-CDH fetus, however, this cannot be a predictor of survival, as the liver is virtually always herniated into the thorax. Further subdivision of degree of liver herniation, manifested by percentage of herniated liver, did not prove to be a predictor of outcome either, as the survival rate was essentially the same (35\% of the liver herniated for survivors, $38 \%$ for nonsurvivors). This is not the case for
L-CDH, where the volume of herniated liver does predict survival (17 vs. $28 \%$ in our previous case study group [1]).

The distribution of survivors in R- versus L-CDH cases is not only different with respect to herniated liver, but also with respect to lung hypoplasia. Unlike with L-CDH, where an O/E TLV ratio of $<25$ denotes a poor prognosis (13\% survivors at our institution [1]), the fetus with R$\mathrm{CDH}$ and an MR-calculated $\mathrm{O} / \mathrm{E}<25 \%$ had a survival probability of $60 \%$ (Fig. 2). In fact, there was no cut-off $\mathrm{O} / \mathrm{E}$ TLV value significant for mortality in our study group of R-CDH. Another marker of pulmonary hypoplasia, the US-calculated O/E LHR, also did not seem to predict outcome in the fetus with R-CDH. The European group, which recently reported an overall survival of 53\% in the group managed expectantly, described a significant increase in mortality if O/E LHR was $\leq 45$ (survival: $17 \%$ ) and O/E LHR was $\leq 30$ (survival: $0 \%$ ) [15]. Our group did not show this trend for O/E LHR $\leq 45$ (survival 60\%); the single case with LHR $\leq 30$ did not survive, although no conclusions can be reached from one case. This discrepancy in O/E LHR values for survival between the US and European groups is important, as an LHR value of $<45$ has been proposed as a marker of severe pulmonary hypoplasia and cut-off value for offering antenatal intervention by means of fetal endoscopic tracheal occlusion [15, 18]. The difference between these outcomes may be based on the relatively low number of cases reported in each center (19 in the European group, 21 with available O/E LHR values at our center) or differences in postnatal clinical protocols and care of the infant between the centers.

These different results in outcome stratified by $\mathrm{O} / \mathrm{E}$ LHR values also raise an important question: Should an O/E LHR of $\leq 45$ still be the guidance for fetal endoscopic tracheal occlusion inclusion for the $\mathrm{R}-\mathrm{CDH}$ fetus or is
16

Fetal Diagn Ther 2018;43:12-18

DOI: $10.1159 / 000464246$
Victoria et al. 
this number center-specific? It is clear that we would not use this number as sole guide for prenatal tracheal occlusion at our institution, as the survival of these fetuses without prenatal intervention is $60 \%$. The final answer to these questions may be better served with a larger study population provided by a multicenter study where similar pre- and postnatal management is utilized.

The use of ECMO was the only postnatal factor evaluated in survival. ECMO is used to treat the most critical neonates in whom conventional ventilatory strategies have failed. In our study, and unlike in the group of L$\mathrm{CDH}$, the use of ECMO does not predict outcome in the fetus with R-CDH, another suggestion that right and left hernias may follow different pathophysiology and are not simply the result of a diaphragmatic defect with subsequent herniation of intra-abdominal organs.

The main limitation of this work is its relatively small sample size. This is due to the fact that $\mathrm{R}-\mathrm{CDH}$ is a rare entity, with this study representing a population seen during a 12-year time period with available prenatal studies. A second limitation of the present study is that this is not a population of isolated $\mathrm{R}-\mathrm{CDH}$ patients, but rather one in which additional abnormalities are present, predominantly heart disease (Table 4), factors that may have contributed to postnatal outcome as well.

The findings in this study suggest that $\mathrm{L}-$ and $\mathrm{R}-\mathrm{CDH}$ appear to behave differently, and that factors that make
L-CDH fatal (low O/E TLV and O/E LHR, high-volume herniated liver, etc.) may not apply to the fetus with R$\mathrm{CDH}$. This is of greatest importance in two clinical case scenarios: (1) when counseling the family with an affected fetus, and (2) when considering fetal tracheal occlusion as therapy for R-CDH. Choosing a population of $\mathrm{CDH}$ fetuses with poor prognosis for whom prenatal tracheal occlusion may be a lifesaving option is easily delineated for L-CDH cases [19-21], but for the R-CDH fetus, it remains unclear.

\section{Conclusion}

In summary, the present study evaluates if prenatal and postnatal factors known to predict survival in the fetus with L-CDH can be extrapolated to the fetus with R$\mathrm{CDH}$. None of these factors were found to predict outcome at our institution. Present findings indicate that, for our center, reliance on the measures used to predict survival in $\mathrm{L}-\mathrm{CDH}$ may not be appropriate when considering an $\mathrm{R}-\mathrm{CDH}$ case.

\section{Disclosure Statement}

None of the authors have any financial disclosure.

\section{References}

1 Victoria T, Bebbington MW, Danzer E, Flake AW, Johnson MP, Dinan D, Adzick NS, Hedrick HL: Use of magnetic resonance imaging in prenatal prognosis of the fetus with isolated left congenital diaphragmatic hernia. Prenat Diagn 2012;32:715-723.

2 Busing KA, Kilian AK, Schaible T, Endler C, Schaffelder R, Neff KW: MR relative fetal lung volume in congenital diaphragmatic hernia: survival and need for extracorporeal membrane oxygenation. Radiology 2008;248:240246.

3 Cannie M, Jani J, Meersschaert J, Allegaert K, Done E, Marchal G, Deprest J, Dymarkowski $S$ : Prenatal prediction of survival in isolated diaphragmatic hernia using observed to expected total fetal lung volume determined by magnetic resonance imaging based on either gestational age or fetal body volume. Ultrasound Obstet Gynecol 2008;32:633-639.

Right Congenital Diaphragmatic Hernias
4 Walsh DS, Hubbard AM, Olutoye OO, Howell LJ, Crombleholme TM, Flake AW, Johnson MP, Adzick NS: Assessment of fetal lung volumes and liver herniation with magnetic resonance imaging in congenital diaphragmatic hernia. Am J Obstet Gynecol 2000;183: 1067-1069.

5 Hedrick HL, Danzer E, Merchant A, Bebbington MW, Zhao H, Flake AW, Johnson MP, Liechty KW, Howell LJ, Wilson RD, Adzick NS: Liver position and lung-to-head ratio for prediction of extracorporeal membrane oxygenation and survival in isolated left congenital diaphragmatic hernia. Am J Obstet Gynecol 2007;197:422.e1-e4.

6 Metkus AP, Filly RA, Stringer MD, Harrison MR, Adzick NS: Sonographic predictors of survival in fetal diaphragmatic hernia. J Pediatr Surg 1996;31:148-151; discussion 151-142.

7 Peralta CF, Cavoretto P, Csapo B, Vandecruys $\mathrm{H}$, Nicolaides KH: Assessment of lung area in normal fetuses at 12-32 weeks. Ultrasound Obstet Gynecol 2005;26:718-724.
8 Dekoninck P, Gratacos E, Van Mieghem T, Richter J, Lewi P, Ancel AM, Allegaert K, Nicolaides K, Deprest J: Results of fetal endoscopic tracheal occlusion for congenital diaphragmatic hernia and the set up of the randomized controlled TOTAL trial. Early Hum Dev 2011;87:619-624.

9 Victoria T, Jaramillo D, Roberts TP, Zarnow D, Johnson AM, Delgado J, Rubesova E, Vossough A: Fetal magnetic resonance imaging: jumping from 1.5 to 3 tesla (preliminary experience). Pediatr Radiol 2014;44:376-386; quiz 373-375.

10 Rypens F, Metens T, Rocourt N, Sonigo P, Brunelle F, Quere MP, Guibaud L, MaugeyLaulom B, Durand C, Avni FE, Eurin D: Fetal lung volume: estimation at MR imaging-initial results. Radiology 2001;219:236-241.

11 Ward VL, Nishino M, Hatabu H, Estroff JA, Barnewolt CE, Feldman HA, Levine D: Fetal lung volume measurements: determination with MR imaging - effect of various factors. Radiology 2006;240:187-193. 
12 Hedrick HL: Management of prenatally diagnosed congenital diaphragmatic hernia. Semin Fetal Neonatal Med 2010;15:21-27.

13 Chiu P, Hedrick HL: Postnatal management and long-term outcome for survivors with congenital diaphragmatic hernia. Prenat Diagn 2008;28:592-603.

14 Victoria T, Andronikou S: The fetal MR appearance of 'nutmeg lung': findings in 8 cases linked to pulmonary lymphangiectasia. Pediatr Radiol 2014;44:1237-1242.

15 DeKoninck P, Gomez O, Sandaite I, Richter J, Nawapun K, Eerdekens A, Ramirez JC, Claus F, Gratacos E, Deprest J: Right-sided congenital diaphragmatic hernia in a decade of fetal surgery. BJOG 2015;122:940-946.
16 Akinkuotu AC, Cruz SM, Cass DL, Cassady CI, Mehollin-Ray AR, Williams JL, Lee TC, Ruano R, Welty SE, Olutoye OO: Revisiting outcomes of right congenital diaphragmatic hernia. J Surg Res 2015;198:413-417.

17 Iqbal CW, Derderian SC, Lusk L, Basta A, Filly RA, Lee H, Hirose S: Outcomes for prenatally diagnosed right congenital diaphragmatic hernia. Fetal Diagn Ther 2015, DOI: $10.1159 / 000369385$.

18 Jani J, Nicolaides KH, Keller RL, Benachi A, Peralta CF, Favre R, Moreno O, Tibboel D, Lipitz S, Eggink A, Vaast P, Allegaert K, Harrison M, Deprest J, Antenatal CDHRG: Observed to expected lung area to head circumference ratio in the prediction of survival in fetuses with isolated diaphragmatic hernia Ultrasound Obstet Gynecol 2007;30:67-71.
19 Deprest J, Brady P, Nicolaides K, Benachi A, Berg C, Vermeesch J, Gardener G, Gratacos E: Prenatal management of the fetus with isolated congenital diaphragmatic hernia in the era of the TOTAL trial. Semin Fetal Neonatal Med 2014;19:338-348.

20 Deprest JA, Flake AW, Gratacos E, Ville Y, Hecher K, Nicolaides K, Johnson MP, Luks FI, Adzick NS, Harrison MR: The making of fetal surgery. Prenat Diagn 2010;30:653-667.

21 Hedrick HL: Management of prenatally diagnosed congenital diaphragmatic hernia. Semin Pediatr Surg 2013;22:37-43. 